\title{
Identifying Barriers faced by Ottawa Somali Youth in Accessing Post-secondary and Vocational Opportunities: An Example of Community-Based Participatory Research
}

\author{
Adje van de Sande, Tara McWhinney, Katherine Occhiuto, Jennifer Colpitts, Ismail \\ Hagi-Aden, Ahmed Hussein, Zoey Feder
}

\begin{abstract}
Aвstract In 2016, with funding from the Ontario Trillium Foundation's Seed Grant program, the Somali Centre for Family Services of Ottawa (SCFS) invited the Centre for Studies on Poverty and Social Citizenship (CSPSC) at Carleton University to carry out a needs assessment focusing on the barriers faced by Somali youth in accessing postsecondary education and employment training opportunities. The main objective of the needs assessment was to address social and economic exclusion locally by inviting Somali youth (ages 19-30) from the Ottawa area to participate in focus groups to discuss the barriers they have faced in accessing post-secondary education and employment training programs, and to invite their views on the supports needed to address these barriers. The CSPSC and the SCFS agreed that the research would involve a participatory action research approach where members of the Somali and Muslim Community would participate on an advisory committee, and where youth from the Somali Community would be directly involved in all phases of the research. Five themes were identified during the analysis: Barriers to accessing post-secondary education; Barriers to accessing job placements and training programs; Barriers to securing employment; A need for a Somali-focused employment resource centre; A need for Somali youth mentors.
\end{abstract}

KEYWORDS participatory action research; employment training; racialized youth; Somali youth; immigrant youth employment

Within Canada, over 80\% of the Somali population is under 30 years of age (Naji, 2012). However, many first and second generation Somali-Canadian youth continue to experience difficulties with integration and social inclusion. Representing an ethnic and a religious minority, the Somali population has become a highly racialized group within Ottawa. The Somali community continues to face alarmingly high rates of poverty, unemployment, and youth crime (Kenny, 2007). In 2011, the unemployment rate for Somali youth 15-24 years of age who were participating in the labour force was 33.4\%, compared to a $16.6 \%$ unemployment rate for labour force participants across Canada of the same age (Statistics Canada, 2011). This highly restrictive access to the labour market makes Somali youth more economically vulnerable, which can further perpetuate cycles of poverty, and exacerbate physical and mental 
health issues as well as high-risk behaviours.

In 2016, with funding from the Ontario Trillium Foundation's Seed Grant program, the Somali Centre for Family Services of Ottawa (SCFS) invited the Centre for Studies on Poverty and Social Citizenship (CSPSC) to carry out a needs assessment focusing on the barriers faced by Somali youth in accessing post-secondary education and employment training and opportunities. In carrying out this research, the Centre's main objective was to address social and economic exclusion locally, by inviting Somali youth (aged 19-30) from the Ottawa area to participate in focus groups to discuss the barriers they have faced in accessing post-secondary education and employment training programs, and to invite their views on the supports needed to address these barriers. The SCFS and the CSPSC agreed that the research would involve a participatory action research (PAR) approach where members of the Somali and Muslim Community would participate on an advisory committee, and where youth from the Somali Community would be directly involved in all phases of the research.

The research process was consistent with the Dudley Model of PAR as explained below (Dudley, 2010). The data collection and analysis were carried out by the research team, which included the principal investigator from CSPSC, three graduate students from Carleton University, and two youth leaders from the Somali community. The research team ran four focus groups to collect input from Somali youth regarding their own experiences in seeking out vocational training and enrolling in college and university programs. Both male and female Somali youth participated in the focus groups, with the research team running three male focus groups and one female focus group. Consistent with the Dudley Model of PAR, the SCFS planned to share the results of this research with all stakeholder groups as the precursor to a larger program design and delivery project for Somali youth.

\section{Background}

Somali youth in Canada face multiple barriers to education and employment opportunities (Ontario Council of Agencies Serving Immigrants, 2016). Limited access to securing employment increases economic vulnerability, which can fuel high-risk behaviours, exacerbate physical and mental health issues, and perpetuate cycles of poverty (Canadian Mental Health Association, 2008). Such high stakes warrant an examination of the barriers Somali youth in Canada face in accessing the labour market, and, by extension, higher education.

A review of the literature reveals a limited availability of research focusing on immigrant (first and second generation) youth experiences in accessing higher education in Canada (Anisef \& Kilbride, 2008; Ferede, 2010). Within the literature available, a recurring theme is lack of access to information on post-secondary education and employment training programs in high schools and community centres in Canadian cities (Anisef \& Kilbride, 2008; Baum \& Flores, 2011; Caidi, Allard, \& Quirke, 2010). Caidi, Allard, and Quirke (2010) refer to this lack of access as "information poverty" (p. 503). Compounding this issue is the fact that many Somali youths' parents immigrated to Canada during the 1980s and 1990s, and did not attend postsecondary schools in Canada (OCASI, 2016). This limits their knowledge of Canada's often complicated social systems, and reduces their ability to support and navigate their children 
through such systems (Baum \& Flores, 2011). Subsequently youth turn to their friends and peer group(s) to obtain information about employment opportunities and education programs (Caidi, Allard, \& Quirke 2010). To overcome this information barrier, Anisef and Kilbride (2008) suggest providing youth with opportunities to be mentored. According to their study, youth commented that having a mentor who could discuss the differences between postsecondary programs or the processes for applying to these programs could critically increase their access to information.

Available literature strikingly points to the lack of support racialized youth experience from their guidance counsellors at school (Anisef \& Kilbride, 2008; City of Ottawa \& City for All Women Initiative, 2016); with implications that these counsellors, along with teachers and administrators, participate in systemic discrimination and racism (Anisef \& Kilbride, 2008; Greater Toronto Civic Action Alliance, 2014; OCASI, 2016; Shakya et al., 2010). While there are reports of discrimination and racism for both sexes, males report higher incidents of discrimination, bullying, and physical violence (Anisef \& Kilbride, 2008; City of Ottawa \& CAWI, 2016; OCASI, 2016). Additionally, Somali males often report being directly or indirectly discouraged by teachers from aspiring to higher education (City of Ottawa \& CAWI, 2016).

While barriers to immigrant youth accessing education have been identified, there are also a number of suggestions available to increase accessibility to post-secondary education. Anisef and Kilbride's (2008) study speaks to increasing the number of teachers from different racial, ethnic, and cultural backgrounds. This same study also emphasises the importance of providing information about education and employment opportunities at the secondary education level, as a means to prepare youth to transition into post-secondary education and to foster spaces where youth can voice their concerns. Additionally, providing opportunities for youth to participate in co-op, practicum, and/or internships can work to build social networks, and provide opportunities to build the skills necessary to succeed in the classroom and within the labour market (Anisef \& Kilbride, 2008; Greater Toronto Civic Action Alliance, 2014).

Research focusing on Somali youth's employment success is similarly sparse compared to the existing research on their educational attainment (Anisef \& Kilbride, 2008; Block \& Galabuzi, 2011; Caidi, Allard, \& Quirke 2010; Greater Toronto Civic Action Alliance, 2014). However, available literature shares a theme concerning racism and discrimination (Anisef \& Kilbride, 2008; Block \& Galabuzi, 2011). When visible minorities find employment, they face what Block and Galabuzi (2011) deem a "persistent colour code that blocks them from the best paying jobs" (p. 3). This experience of discrimination contributes to the income gap by creating barriers for visible minorities in obtaining well-paying and secure jobs (Block \& Galabuzi, 2011). The literature also points to a lack of social connections as an ongoing barrier to obtaining employment (Anisef \& Kilbride, 2008; Greater Toronto Civic Action Alliance, 2014). While those with established roots in Canada may rely on connections to get their feet in the door, first and second generation immigrant families may not have the same established roots in their community or the job market (OCASI, 2016). Of note is how government employment programs are not the all-encompassing solution. Anisef (as cited in Anisef \& Kilbride, 2008) notes how such programs can inadvertently label youth participants as "at- 
risk", making these youths less attractive to employers.

There has been a number of suggestions made to potentially increase immigrant youth employment rates. Similar to the suggestions made within the literature concerning postsecondary education, mentorship was a common theme in relation to reducing employment barriers (Greater Toronto Civic Action Alliance, 2014; Anisef \& Kilbride, 2008). Providing a mentor who can share information on how and where to find employment, and the skills necessary to succeed in the workforce, can increase immigrant youths success by providing support and information (Greater Toronto Civic Action Alliance, 2014). Furthermore, having a mentor from one's own culture, who can relate to the culture clash that many youth report experiencing, can be beneficial (Anisef \& Kilbride, 2008; Greater Toronto Civic Action Alliance, 2014; OCASI, 2016). This research also suggests how co-ops or practicum opportunities bear great potential for employment success (Anisef \& Kilbride, 2008; Greater Toronto Civic Action Alliance, 2014). Through such opportunities, youth can connect with their community and employers without the attachment of an "at-risk" label (Anisef \& Kilbride, 2008; Greater Toronto Civic Action Alliance, 2014). Flexibility within employment opportunities is also recommended, so programs can better respond to the needs, concerns, and experiences of immigrant youth populations. Anisef and Kilbride (2008) advocate for culturally-specific programs to be established and led by professionals of the same racial, ethnic, or cultural background as the youth, providing spaces where culturally sensitive topics can be discussed. Also suggested, as a mechanism to reduce barriers, is the idea of providing a central hub youth can visit to obtain information on employment opportunities and to learn about the job market (Greater Toronto Civic Action Alliance, 2014; Anisef \& Kilbride, 2008).

As has been stated, there is a lack of literature exploring the needs of immigrant youth in obtaining employment and post-secondary education in Canada. The study conducted by Anisef and Kilbride (2008) specifically explored these experiences, and as such our literature review leaned heavily on their results. However, because their study did not specifically explore the experiences of Somali youth, we cannot assume that the needs identified in their study will be reflective of the experiences of Somali youth in Ottawa.

\section{Methodology}

The entire research project was conducted using the Dudley Model of PAR (Dudley, 2010) where each stage of the research process and decision making included the involvement of a Research Advisory Committee with representatives from the Somali and Muslim community and two Somali youth. The ultimate objective of the research was to create the necessary resources and/or programs to support Somali youth to both access and succeed in postsecondary programs and employment paths; a PAR design was chosen to inform changes, transformations, and/or the creation of youth-directed services that could sustain better outcomes. This was motivated by the understanding that with greater input and investment from the community, the more likely service implementations are to succeed. The Research Advisory Committee met several times from October 2016 to February 2017 to discuss the aims and design of the research and to seek and secure research funding. The Research 
Advisory Committee decided to conduct a participatory needs assessment to gain new insight into the real, rather than perceived experiences of Somali youth within the Ottawa region. In addition to the Principal Investigator, two female $\mathrm{PhD}$ students and one female Masters student associated with Carleton University were hired for the participatory needs assessment. Following the Dudley Model of PAR, the research team also included two male Somali youth, both of whom had undergraduate degrees, and one of whom was also a Masters student.

Focus groups were chosen for the needs assessment, as this method allows for the collection of large amounts of data in a short period of time and would provide information on the motives, attitudes, and opinions of Somali youth (Carey, 2013). The focus group data collection took place over the course of two weeks. Once ethics clearance was provided by the university's research ethics board, the team ran four focus groups to collect input from Somali youth. Each group ranged from six to ten participants, with 32 individuals participating overall. Participants ranged in age from 17 to 30, and the study was conducted in English. Both women and men participated in the data collection, with the research team running three focus groups for men and one for women. The two $\mathrm{PhD}$ students had extensive experience in running focus groups, and one of the Somali youth also had experience with focus group moderation. The research team met to discuss facilitation techniques, and those with experience provided modelling for the other research assistants. The selection of participants was carried out by the two team members of Somali background. Using a snowball sampling technique, these individuals recruited their friends, as well as members of Somali youth groups in the Ottawa area. Each of the three focus groups for male youth was facilitated by one female research assistant and one male Somali research assistant. The focus group for female youth was facilitated by two female research assistants from the university. The female youth participants expressed a preference for having only female facilitators, and therefore there was no community researcher as a facilitator for this group (as the two Somali youth on the research team were male).

The focus group narratives were analyzed using a General Inductive Approach (Thomas, 2006) using NVivo, a qualitative data analysis software program. The two PhD students and one of the Somali youth research assistants were familiar with NVivo and had used it previously on research projects. Further training on NVivo was available to all research assistants at Carleton University, and was attended by the two Somali research assistants and one of the $\mathrm{PhD}$ students. The two Somali research assistants and two of the university research assistants each transcribed one of the four focus groups. The research assistants who transcribed the focus groups also provided a preliminary coding of the data. Employing the General Inductive Approach, this preliminary work was based on a careful reading of each line of text to identify and code several common themes and subthemes that related to the research topic. Some selections of text were coded multiple times, and non-relevant text was not coded. The transcription and data analysis of each focus group was shared between all five research assistants. These separate analysis results were then further refined at a meeting of the entire research team. A general consensus was formed as to the merging and organizing of codes into major themes and subthemes. After this meeting one of the $\mathrm{PhD}$ research 
assistants merged the separate coding results in NVivo and selected text highlights for the research report based on the agreed thematic results.

\section{Findings and Discussion}

\section{Barriers to Accessing Post-Secondary Education}

As stated in Anisef and Kilbride's (2008) research, a specific barrier to employment and socioeconomic advancements was lack of education. However, at the time of the focus groups, most of our research participants were attending or had attended post-secondary education programs, mostly within universities. The general consensus emerging from this project was that post-secondary education is highly valued in the Somali community, so youth are often encouraged or pressured by parents to attend:

I know specifically post-secondary education is something we're all pushed towards. So if a mother sees you, [and] you're not going to a post-secondary education, then what are you doing with your life? You kind of failed them that's taught as well.

...Especially with Somali parents who have immigrated here, there is a big influence on children coming to university; the main goal isn't to find a program they like, but they put pressure on them instead to just get into university. So a lot of Somali youth feel pressure to just get into university instead of finding out what they like and, you know, which program would be best for them. So I think that also kind of affects Somali youth.

The first quote demonstrates the pressures youth can feel in regard to attending university, by connecting a lack of post-secondary education with a failure to meet their parents' expectations. As explained in the second quote, when youth are pressured to attend university they may choose a program without a good understanding of what career path they want. One participant expresses below how the choices youth make regarding education are decisions they will have to live with their whole lives:

I think my goal, mostly, is [to] finish school. Well, finish school in a program [that] I like [because] [...] our parents, [...] they have opinion[s] about our future, they say, 'Oh, you should do this', [and], 'Oh, you should do that'. But at the same time, you want to do what you want to do. [...] When you look back, when you look forward, like, 30 years and you're in your job... it's not their job, it's your job. So I just want to do something that I want.

Another recurring theme within the focus groups was the lack of knowledge among Somali immigrant and refugee populations concerning post-secondary education. As pointed out by Baum and Flores (2011), many of their parents have not attended post-secondary school in 
Canada, and are therefore limited in supporting their children in navigating the educational system. Participants highlighted the need for increased knowledge of existing education and training programs to make informed choices on how to work towards obtaining a meaningful career. The following two quotes express how participants feel theirs parents and elders don't understand the education system in Canada:

I think it has more to do with the fact that there is not much guidance from guys, especially the older men in our community because they are not really familiar with this type of system, especially with the background they come from, they don't understand the schooling system very well. And also kids these days are growing up [and] they don't really have someone to point them in the right direction when it comes to their school.

Yeah, especially, I feel like for me, my parents, they were refugees. They didn't go to post-secondary. I'm the oldest, so I was just thrown into this whole new world not knowing exactly what I was getting myself into.

As demonstrated in these statements, most of the youth in this study feel their parents are unable to help them navigate the education system, due to their lack of experience with formal education — and yet, these youth felt strongly pressured to pursue post-secondary programs. They expressed the need for more guidance on deciding whether to attend post-secondary programs, as well as finding programs and classes that lead to meaningful employment.

The focus on university within the Somali community may also stem from the greater availability of supports for these types of programs. For example, there were few focus group participants studying in the trades:

In our community, it is never really an option. It's post-secondary education or bust there is no real-I guess parents are more open now to trade: there is really good money in it. [But] there isn't enough training or support for trade stuff.

While we can see that choosing the trades is increasingly being accepted as a good career choice by Somali parents and youth, the availability and lack of knowledge regarding trade programs and financial supports for these programs affect youths' choice in attending. Financial supports and knowledge on accessing vocational programs are essential if this is to be an option for Somali youth. As highlighted by the Ontario Council of Agencies Serving Immigrants (2016), those with established roots in Canada can rely on connections to get their feet in the door; youth of first generation immigrant families may not have the same established roots in the community or job sector. Of note, this limited access to trade programs was also discussed heavily by the project's Advisory Committee. Advisory Committee members pointed out that in order to attend trade schools in Ottawa, an individual often needs to have 
an apprenticeship arranged with an employer before they can be accepted into a program. This creates a huge barrier to Somali youth, who as immigrants have limited networks to find and secure apprenticeships.

Another common theme was that Somali youth focus too much on specific types of postsecondary programs:

Speaking about culture, there's this thing in our community-education is good. We focus on specific programs. What I'm trying to get at is - I met a brother who did water waste management. He went to Algonquin. You don't see a lot of Somalis doing that; a very essential program. People need that, right? But we keep on going to the same programs. We have to open our focus.

This focus group participant discussed how, once one community member is successful in a program, others tend to follow in the hopes of obtaining a successful career. For this participant, this type of cycle narrows the educational and employment possibilities for Somali youth, discouraging individuals from carving out new and alternative paths for themselves. In another focus group, the tendency to follow in others' footsteps was viewed as a positive outcome, and participants discussed how seeing a community member thrive in a specific educational program motivates youth and encourages parents to broaden their views.

Many participants in the focus groups discussed how post-secondary programs should focus on job readiness, so that what is taught in school translates to the workplace. Youth in this study experienced a disconnection between education programs and the skills/knowledge employers are looking for:

For university programs, what they do is, a lot of times, they teach you material that doesn't really translate to your workplace...like, you don't have the necessary skills in order to work for certain jobs. And, most of the time, what they are looking for is a student who has experience in the field. So [if] you don't have that, it kinds of puts you at a disadvantage, unless you are a co-op student and [have] been in the situation where you've been working in the field.

Most of the time, when you are trying to apply for jobs, you need certain skills and especially when you are a student, all you have done is really [study] and gain knowledge. But you don't have any practical skills.

For research participants, the goal in pursuing education was to graduate and obtain meaningful, well-compensated employment. Yet, as the quotes above demonstrate, most of the participants with experience in post-secondary education did not feel they are/were being well equipped beyond their educational credentials to compete for employment within their chosen fields.

Somali youth also face unique challenges when trying to obtain employment. Consistent 
with those issues mentioned earlier (regarding support in choosing an educational program), youth in the Somali community feel they do not have the same supports as their peers in transitioning into employment. Their counterparts often receive greater guidance from their parents, who have been through Ontario's post-secondary education system and have longestablished careers:

For the Somali youth, it's a tough battle because the other kids in the education system, their parents are here for three to four generations. Their parents give them the first job - from how to fill out a resume. Our situation - other families from other countries — it's starting from the ground up. They don't have someone to show them how to make a resume, how to find your first job; everything is learning on the fly as you go.

After completing post-secondary education, some of the youth in this study indicated an interest in entrepreneurial programs. Some of these participants indicated that they themselves developed a real interest in entrepreneurship, while others suggested it was popular for Somali youth to decide to participate in entrepreneurial training programs because of the resources that are uniquely available to these program participants:

My goal is to build up some stability, like what he said. Trying to own some companies of my own...working on a few ideas at the moment. Like he said, I do not believe in formal education; there are other ways to attain your goals besides university.

He was talking about different government grants that are given in Ottawa for just entrepreneurship itself. There's a ridiculous amount of grants you can do, it's crazy - especially between 18 to 29. If you have a business idea or something, you can go [to] Invest Ottawa. Talk to them; they definitely give you some research. They tell you this is what you need to do-different stages of your business. If you get in as a portfolio company, you get access to an earmark fund which is $\$ 20000$.

As the statements above indicate, not all the Somali youth in this study preferred formal education. Entrepreneurial programs are perceived as providing an alternate path to employment. Several participants expressed an interest in learning more about what was involved in starting one's own business. Although not discussed by study participants, a preference for entrepreneurial programs could potentially be associated with a lack of hope in obtaining meaningful employment within the current labour market.

\section{Barriers to Accessing Job Placements and Training Programs}

Many of the Somali youth in this study have taken part in job placement programs such as 
the federal government's Federal Student Work Experience Program (FSWEP) and the Youth Services Bureau's (YSB) Youth Job Connection program. FSWEP provides youth with work experience in the federal public service, while Youth Job Connection offers workplace training and a short-term job placement. Other programs the youth in this study have accessed, such as Youth Futures and services at the YMCA, provide assistance with job searching and admission to post-secondary education. Although study participants appreciated such support as assistance with resume writing and the chance to acquire summer employment, many expressed a need to have more job placement opportunities that specifically align with their chosen career path:

If you are hired for the summer, the majority of the funding goes to communityoriented organizations that hire individuals for community-oriented jobs. But, if you are in engineering and you are working at some community-oriented organization for the summer, what benefit is that to you? You [get] a job, you [get] paid and [you get] a bit of experience, but [you get] nothing towards what you want to do in life.

While participants shared a general sentiment of appreciation for community work, they also expressed how these opportunities are not equipping them with the skills they really need to obtain jobs in the private market. One participant raised concern over the stigmatization faced by youth involved in job placement programs geared towards low-income youth. This echoes the concerns of Anisef (as cited in Anisef \& Kilbride, 2008), that some of these programs inadvertently label youth as "at-risk" and makes them less desirable job candidates. The following statement reflects the sentiments mentioned earlier, about feeling that summer employment does not truly aid youth beyond providing them with short-term employment:

If I want to work for a bank, but I get summer employment working at a community agency], what good is that to me? [...] It is a double-edged sword. You come from a low-income neighbourhood, and it is right there on your resume. You live in a low-income neighbourhood and the only employment you ever had was summer-funded programs [...]. It is like the city's way of shutting people up. You know what this is? What we are doing? We are throwing money at these organizations and they are going to hire your kids for the summer. What benefit does that do?

In this quote, the participant points out how employers benefit from public funding for youth employment by obtaining low-cost labour, but questions the actual long-term benefits for the youth within these programs. Some participants discussed the possibility of an employment program that would let Somali youth choose exactly where they wanted to work (including within the private sector). One participant with experience in such a program briefly expressed that it was a positive experience for them. 
As with education, the youth in these focus groups want job training to provide skills related to their field of study or chosen career path:

Training should include the skills and experience employers want.

Um, sometimes I feel like, ah, if you have no experience at all, and all they do is offer you trainings, then [...] trainings aren't going to fill up your resume, unfortunately, you know? So maybe if they offered experience...

In the second quote above, a participant explains how popular one-day, short-term training programs are not helpful in providing the skills needed to secure employment. Without the experience employers are looking for, youth have a hard time accessing employment in their field, even with post-secondary education.

Participants expressed limited opportunities for Somali youth to connect with employers or other professionals from private corporations. As one participant discusses, the private sector was seemingly the hardest to succeed in:

There are different barriers in different sectors. There are fewer barriers in the federal government - just by seeing how many Somali Canadians [are] working there. But you will rarely ever see a Somali person in a Fortune 500 company or [in] any sort of private [corporation]. It is like a gentlemen's club that we are not invited to.

The federal public service has been easier for Somali youth to access as the Federal Student Work Experience Program (FSWEP) provides a federal public service placement program. The federal government also notably has employment equity policies in place. By contrast, participants expressed feeling that positions within the private sector were significantly more difficult to obtain without specific job skills or, more importantly, networking and connections.

The question of when exactly job placement and training programs should be available came up in several of the focus groups. Placement programs, like the Youth Job Connection, are mainly accessed by youth when they are in high school, and those who are in post-secondary education tend to be more familiar with FSWEP. One focus group suggested that information on the FSWEP program be made more available to high school students, so that they could access the program earlier in their post-secondary education. Another focus group discussed how job placement programs should be available to those who have finished school and are looking to kick-start lifetime careers:

Also, maybe, they already finished school, [are] finishing, like, post-secondary education, or any other-like, even college... the ones who are in school, $[. .$. [or] finished program[s] — doesn't matter. As long as you are not high school, you know... you are actually looking for a career job, you know, to establish life, 
you know, or maybe get married or something, you know, like that.

The consensus within this study is that job placement programs are readily available for those in school rather than for those who are job searching after completing post-secondary education:

\begin{abstract}
When I am looking for an internship, it is a lot easier to find a co-op than it is to find a full-time job, right? So when people have graduated-[...] I can get more experience than them just because I am a student, because I am going back to school, while they can't get any internships or find a job. A lot of people looking for jobs are not in school, and then they can't get anywhere with any of these programs because they are not in school.
\end{abstract}

Co-op programs and internships are often available within post-secondary education programs. Therefore, students have a much easier time accessing these types of opportunities than those that have completed their education. However, participants also indicated problems with internships and co-op programs that coincided with post-secondary studies. Some participants had difficulty acquiring a placement while being a student. Others could not afford to work unpaid and attend school at the same time, and sometimes, fitting the placement into a busy school and work schedule was just not feasible.

\title{
Barriers to Securing Employment
}

Anisef \& Kilbride (2008) found that males reported higher incidents of discrimination, bullying, and physical violence. Barriers to employment were raised by the male youth in this study specifically regarding discrimination and criminal records:

What is going on in the media with the Somali youth and the violence puts a negative image on all Somalis, so everybody [...] will have the pre-notion that, "Ok, these people come from this type of background", instead of actually giving us a chance.

There are so many times a young kid is labeled something, and then, because of that label, they sort of adopt that kind of behaviour and that track throughout [their life]. If you're, like, a youth and you incurred a criminal record on one of the many dumb, stupid things that could happen - as a youth, if you do something. And then you incurred a criminal record and then that stays with you... and then suddenly all of those opportunities have narrowed like this...

Participants in our sample expressed that discrimination and labeling of Somali youth within Ottawa creates serious obstacles to employment and opportunities, and the youth who actually incur a criminal record will have an even harder time finding employment in the future. 


\section{A Need for a Somali-focused Employment Resource Centre}

When considering what types of supports could help to alleviate some of the issues raised regarding education and job training programs, the youth in this study overwhelmingly favoured the creation of an educational/employment centre or resource program to run within a pre-established service centre. Providing a central location where youth could visit to obtain information on employment opportunities and learn about the job market was one of the recommendations mentioned in the report by the Greater Toronto Civic Action Alliance (2014). Some participants wanted this resource program/centre to be specifically for Somali youth. Others felt that making it specifically for Somali youth would only further stigmatize this population. Currently, Somali youth find it difficult to know what programs are available to them:

With all of these employment, um, services-they're not interconnected. Like, do they know what the others [are] offering, so that they can move effectively? And are they sending people to each other? If they're not, then everybody's doing something in their own silo; nobody's letting each other know.

The quote above described a shared consensus that employment programs are fragmented, and that it is difficult to know what is available across Ottawa. Youth expressed frustrations that centres do not communicate information about one another to service users. The youth in this study also indicated that they are not being informed about available opportunities in a timely manner:

Yeah, I think for me, it was um-like, I heard about FSWEP, like, when I was in high school. But the only reason I heard about it was because, like, I knew a girl. I just happened to know her and was like — she graduated and she got a job through FSWEP, so she told me to apply in my first year. And now I'm in third year and I finally got it, you know?

They're not good at getting the word out, at all. They have deadlines, [and] nobody knows about the deadlines until it's too late.

But the problem is, like, right now, these kids don't have, um-they're not told when the deadline is. So they don't even know when to sign up.

I found out — that's the thing — I really don't think that there's a way to find out about these things. I found out through somebody, who found out through somebody...

The youth expressed that a single place to access thorough information regarding education, training and employment opportunities, including important deadlines, would be helpful. This 
type of support would help Somali youth to better prepare and plan for the future:

If you're about to go into university [and] don't know what to take, you can come here and we'll give you guidance; if you're looking for a job and just graduated, come here and we can set up your resume. We can hook you up with our network of people. I can guide you [and] probably take you to the right direction.

The participants also expressed a desire to have this centre or resource program run by workers from the Somali community, or by those who have an understanding of their culture and experience:

...Yeah, counsellors that understand where we come from and the problems that we deal with. Because most people, most of the older generation, don't really come from [the] type of mind-set we come from. They only think traditionally, and how they did it back in the day. So it would be good to have people who understand us now, and understand this day and age.

And I think that the community centre idea-parents will push their kids to these centres if they know it is being run by, for example, the Somali Centre, where they know the guy who is running it. My parents are more willing to send me towards a program that is run by Somalis because they know the people running it.

All the youth in our study wanted those who work in the centre/resource program to have an understanding of their culture and the unique experiences contemporary Somali youth face. As the second quote above indicates, youth feel that their parents would be more likely to encourage them to seek assistance from a centre/resource program if it were to be specifically for Somali youth and run by Somalis. There was some debate as to whether the staff should be youth as well (under 30 years old), but most indicated that age did not matter as long as the staff are able to relate to Somali youth. There were also conflicting views within the focus groups regarding where such a resource centre/program should be located or housed. Some preferred to have it within a post-secondary institution, while others felt if should be placed within the Somali community.

\section{A Need for Somali Youth Mentors}

Another strong theme within the study was the great need for Somali youth to have mentors who can help to guide them through education and employment decisions:

If we had more mentors out there, especially these older students who are graduated coming back, you know, trying to help the youth and explaining the 
process of how to choose which courses to go into, and what programs, and how to go about finding jobs...

This participant states the need to find individuals who can both relate to Somali youth, and who have knowledge of the education system and job searching in Canada. Mentors were also proposed by Anisef \& Kilbride (2008), who suggested that having a mentor available may help guide immigrant youth in seeking out education. The current lack of mentors within the Somali community was a subject heavily discussed in all four of the focus groups. Focus group participants expressed the importance of having mentors and professional connections that can relate culturally:

So, the thing is, like, if who you're working with doesn't get you, they don't get your boundaries, like, I can't even blame him... because he doesn't understand me, he doesn't understand my culture. He doesn't understand my race, he doesn't understand my - he doesn't understand at all, and he [maybe] doesn't want to $[. .$.$] understand.$

Some participants talked about experiences within existing youth programs involving personal support workers who were unable to culturally relate to Somali youth. Many participants felt the need for mentors from within their community, who would be available to support education and career choices both before and after post-secondary education. When discussing mentors, the importance of connections and networking came up as well:

Networking is not what we think it is. It's not me sitting down with someone for a coffee and picking their brain asking them what they want to do. There are real barriers that we face in the Somali community. There aren't many people, older people in higher positions who can facilitate not only conversations, but opportunities. It is fine to have a blueprint of what you want to do in life, but if you have constant barriers and do not [have] real resources to attain those things, you are not going anywhere.

Because I think it's all about connection- when you get down to the nitty gritty of applying for positions. It's about who you know, you know? And, um, if you don't know anybody, what are you going to do?

As these participants indicate, finding employment is often aided by knowing someone in a specific field or company, who can vouch for you and connect you to other professionals. Mentors are desired not only to discuss educational and employment goals, but ideally to connect Somali youth to industries and organizations of interest. 


\section{Conclusion}

This research project supports and expands upon the findings of previous research among first and second generation immigrant youth in Canada. That previous research found a narrowing of employment and training opportunities due to a lack of knowledge of the Canadian education system and training programs (Anisef \& Kilbride, 2008; Baum \& Flores, 2011; Caidi, Allard, \& Quirke, 2010), a scarcity of connections and networks for job-seeking (Anisef \& Kilbride, 2008; Greater Toronto Civic Action Alliance, 2014), discrimination (Anisef \& Kilbride, 2008; Block \& Galabuzi, 2011), and issues with current job placement programs (Anisef \& Kilbride, 2008). Many of our youth participants expressed how their family members and community members have a general lack of experience with post-secondary education and training programs in Canada. The job placement programs most of these youths have experienced did not provide them with skills related to their chosen careers. Many expressed the desire for more opportunities in the private sector. Discriminatory hiring practices and labelling of Somali youth as "at-risk" were also identified by many within the focus groups as barriers to employment and training opportunities. This consistency of findings across immigrant and refugee research indicates the possibility of applying research findings from immigrant and refugee youth populations, such as Anisef and Kilbride's study to issues facing Somali youth seeking education and employment opportunities.

One notable difference between the literature and this Somali youth-focused research project was the high rate of interest and participation in post-secondary education by the youth who participated in our focus groups. Anisef and Kilbride (2008) found a lack of education among immigrant youth, and Shakya et al. (2010) noted that post-secondary education was not a priority for immigrant youth. The high ratio of university-educated participants in this study could be attributed to the snowball recruitment method employed or may reflect a tendency among Somali youth to favour university education. These results may also reflect how many of the research participants were familiar with the Somali Centre for Family Services, and therefore well connected to community supports. Future participatory research approaches with Somali youth should also carefully consider the research recruitment methods, and seek ways to include youth who may be less connected to existing community supports. Even though many of the research participants were familiar with post-secondary education, there was still a consensus among research participants that first generation Somali youth needed more knowledge of educational and training opportunities and choices.

With respect to limitations of the study, as stated above, the selection of the participants was carried out by two Somali youth researchers. Because they used a snowball sampling technique, the participants selected for the study tended to be those they were connected to through their community involvement or education. As a result, the youth engaged in the project tended to be highly educated and actively involved within their community. The research team felt these participants were not fully representative of the Somali youth in Ottawa, many of whom live in poverty and have had poor experiences at school and work. In future studies, it would be useful to look for ways to recruit a more diverse group of participants.

Nevertheless, the findings of this research project align with the recommendations from 
previous research on immigrant youth and refugee populations (Anisef \& Kilbride, 2008; Greater Toronto Civic Action Alliance, 2014; OCASI, 2016). Our youth participants expressed a need for mentors to assist with education and employment choices through providing guidance, resources, and networking connections. Participants did not all agree on whether the mentor needed to be from the Somali community.

Consistency between this research project and those outlined in the literature review highlights the need for the implementation of research recommendations to provide employment and education resources for immigrant youth, as common issues persist. The recommendations of this research project to address these concerns include:

1. The creation of a Somali-focused employment and post-secondary education resource program.

2. The development of a mentorship program for Somali youth.

3. Ensuring the staff person in the resource program could offer private sector liaison.

4. Offering subsidized placement opportunities for Somali youth to design their own placements.

Applying a PAR approach, the Research Advisory Committee has continued efforts to promote the research findings, and to seek funding to follow through on the recommendations. The results of this research project were presented at a special event held at the Somali Centre for Family Services that included the Executive Director of Somali Center for Family Services of Ottawa, members of the Advisory Committee, the research team, a member of Provincial Parliament, and representatives of the Ontario Trillium Foundation. The has already acted on recommendation 2 - the development of a mentorship program for Somali youth through obtaining funding to develop a mentorship program to help Somali youth navigate the post-secondary, and the CSPSC has been invited to evaluate this new program.

In a press release, the Executive Director of the SCFS, Abdirizak Karod, stated, "Thanks to financial support by Ontario Trillium Foundation (OTF) and the support from the government of Ontario, now the Research Report gives us the opportunity to use this evidence-based information to engage our youth for better employment and trades training, while also endeavouring to secure the resources needed to make this undertaking a success". In the same press release, Hon. Member of the Provincial Parliament John Fraser stated, "Research like this empowers organizations such as the Somali Centre for Family Services to better understand social and economic exclusions faced by a specific group in our society and provides governments with data to better address these exclusions" (CSPSC, 2017).

In our effort to identify the barriers faced by Somali youth in accessing post-secondary education and employment, we believed that only a participatory action approach (Dudley, 2010) would provide the Somali community with information that was useful and culturally relevant. While the Principal Investigator and the graduate students contributed the research knowledge and experience needed to carry out the study, the research team was fully committed 
to the idea that the control and ownership of the study belonged to the Somali community. In this respect, we believe our study was largely successful.

\section{About the Authors}

Jennifer Colpitts has an MSW and is working as a counsellor with people suffering from PTSD. She worked as a Research Assistant on two research projects, one with Shepherds of Good Hope and a second with the Somali Centre for Family Services.

Zoey Feder holds a BSW and is working as the administrative assistant for the Centre for Studies on Poverty and social Citizenship. She has experience in working with non-profit organizations dedicated to the eradication of poverty.

Ismail Hagi-Aden holds a Bachelor of Commerce degree with a specialization in Entrepreneurship. He is working on his next business by merging his passions for business and personal development.

Ahmed Hussein has a BA in International Development and Globalization and an MA in Public and International Affairs. Currently, he is a desk officer with Global Affairs Canada. Ahmed's goal is to enable the potential of youth and to support their journey in becoming successful professionals, leaders, and global shapers.

Katherine Occhiuto is a doctoral candidate with Carleton's School of Social Work, a mental health counsellor at a community resource centre, and a research assistant with the Centre for Poverty and Social Citizenship, the SIM Social Work Research Lab, and YouthREX.

Tara McWhinney is a doctoral student with the School of Social Work at Carleton University. She works with the Centre for Studies of Poverty and Social Citizenship and has a keen interest in community-based participatory research.

Adje van de Sande (corresponding author) is an associate professor at the School of Social Work at Carleton University and Chair of the Centre for Studies on Poverty and Social Citizenship. He is the principal author of Research for Social Justice: A Community-Based Participatory Approach, published in 2017. Email: AdjeVanDeSande@cunet.carleton.ca 


\section{References}

Anisef, P., \& Kilbride, K. M. (2008). The needs of newcomer youth emerging "best practices" to meet those needs: Final report. Toronto: Joint Centre of Excellence for Research on Immigration and Settlement, York University.

Baum, S., \& Flores, S. M. (2011). Higher education and children in immigrant families. The Future of Children, 21(1), 171-193.

Block, S., \& Galabuzi, G. E. (2011). Canada's colour coded labour market: The gap for racialized workers. Ottawa: Canadian Centre for Policy Alternatives.

Caidi, N., Allard, D., \& Quirke, L. (2010). Information practices of Immigrants. Annual Review of Information Science \& Technology, 44(1), 491-531.

City of Ottawa \& City for All Women Initiative (CAWI). (2016). Racialized people: Equity \& Inclusion Lens Snapshot. Retrieved from http://www.cawiivtf.org/sites/default/files/racialized_people_ snapshot_en_2016_final_acc.pdf

Canadian Mental Health Association (CMHA) Ontario. (2008). Strategies for reducing poverty in Ontario. Retrieved from http://ontario.cmha.ca/documents/strategies-for-reducing-poverty-inontario

Carey, M. (2013). The Social Work Dissertation. Using Small-Scale Qualitative Methodology (2 ${ }^{\text {nd }}$ ed.). New York: Open University Press.

CSPSC. (2017). Barriers Faced by Somali Youth in Accessing Post-Secondary Education, and Employment Training and Opportunities [Press Release]. Retrieved from http://cspsc.ca/wp-content/ uploads /2018/03/Press-Release-on-OTF-Recognition.pdf

Dudley, J.R. (2010). Research methods for social work: Being producers and consumers of research ( $\left.2^{\text {nd }} e d.\right)$. Boston: Pearson.

Ferede, M. K. (2010). Structural factors associated with higher education access for first-generation refugees in Canada: An agenda for research. Refuge, 27(2), 79-89.

Greater Toronto Civic Action Alliance. (2014). Escalator jobs for youth facing barriers: Companies and youth moving up in the world. Retrieved from http:/ /www.civicaction.ca/wp-content/ uploads/2015/08/EscalatorReport2014.pdf

Kenny, M.E. (2007). The integration experience of Somali refugee youth in Ottawa, Canada: "Failure is not an option for us", (Master's thesis, Carleton University). Retrieved from Carleton University Research Virtual Environment (b2457599)

Naji, L. (2012). Integrating young Canadians of minority backgrounds into mainstream Canadian society: the case of Somali youth. Ottawa: Metropolis Project.

Ontario Council of Agencies Serving Immigrants (OCASI). (2016). Somali refugee resettlement in Canada. Paper presented at the National Metropolis Conference on Getting Results: Migration, Opportunities and Good Governance, Toronto, ON. Retrieved from http://ocasi.org/sites/ default / files/OCASI_Presentation_Somali_Resettlement_Metropolis_2016.pdf

Shakya, Y. B., Guruge, S., Hynie, M., Akbari, A., Malik, M., Htoo, S., Khogali, A., Mona, S.A., Murtaza, R., \& Alley, S. (2010). Aspirations for higher education among newcomer refugee youth in Toronto: Expectations, challenges, and strategies. Refuge, 27(2), 65-78.

Somali Canadian Youth Matter. (2016). Retrieved from https://somaliyouthmatter.com 
Statistics Canada (2011). Ethnic origin (101), age groups (10), sex (3) and selected demographic, cultural, labour force, educational and income characteristics (327) for the population in private households of Canada, provinces, territories, census metropolitan areas and census agglomerations, 2011 National Household Survey [99-010-X2011036]. Retrieved from http://www12.statcan.gc.ca/nhs-enm/2011/dp$\mathrm{pd} / \mathrm{dt}$-td/Rp-eng. 